\title{
The Veterans Health Administration Patient Aligned Care Teams: Lessons in Primary Care Transformation
}

\author{
Robert J. Reid, MD, PhD and Edward H. Wagner, MD, MPH
}

Group Health Research Institute, Seattle, WA, USA.

J Gen Intern Med 29(Suppl 2):S552-4

DOI: $10.1007 / \mathrm{s} 11606-014-2827-8$

(c) Society of General Internal Medicine 2014

\begin{abstract}
A $\mathrm{s}$ the nation moves rapidly to implement the patientcentered medical home (PCMH), the successes and challenges experienced by the nation's largest $\mathrm{PCMH}$ demonstration - the Veterans Health Administration (VHA)'s Patient Aligned Care Team (PACT) model-are particularly salient. In this initiative, over 7,000 primary care teams across the nation are in the process of transforming their operations. ${ }^{1}$ The collection of papers in this supplement provides a window into this complex system redesign during its first few years. Many findings mirror those of other PCMH demonstrations, despite a context of organizational supports and challenges that is atypical of most US practices. Other findings show lessons learned about taking $\mathrm{PCMH}$ rapidly to scale in large systems. These findings are likely to be useful to others contemplating or engaged in transformation.

Together with payment reform, the $\mathrm{PCMH}$ represents a consolidation of two models of primary care design ${ }^{2}$ - the pediatric medical home that emphasizes the base attributes of good primary care, and the chronic care model that describes the necessary care delivery structures and processes. Primary care practices, including those of the VHA, must revise roles and care processes to move from current reactive, episodic approaches guided by a single clinician to team-based, proactive, continuous, and coordinated care. But moving from 'here to there' is a complex, intense, and lengthy endeavor. ${ }^{3}$ We previously described eight largescale changes that must be planned, implemented, and sustained to achieve PCMH transformation: (1) engaging leadership in meaningful change, (2) deploying evidencebased quality improvement and change strategies, (3) empaneling patients to establish care accountabilities, (4) shifting to team-based rather than clinician-directed continuous care, (5) promoting patient-centered care interactions, (6) deploying strategies to enhance the uptake of evidencebased chronic, preventive and acute care, (7) ensuring access of patients to their care teams, and (8) establishing care coordination strategies to ensure timely and informed care handoffs. ${ }^{2}$ Most of the papers in this supplement focus
\end{abstract}

Published online April 9, 2014 on the challenges and successes in implementing one or more of these changes, and show their interdependencies and tradeoffs.

Engaging leadership in meaningful PCMH change is necessary, but often challenging. ${ }^{4,5}$ While the VHA is often thought of as a top-down system in which central leadership can simply mandate change and it will happen, the papers by Tuepker, Forman and colleagues confirm that leaders at multiple levels need to be visible, share a compelling vision, and demonstrate a long-term commitment to change to engage clinicians and staff. In addition, while the VHA centrally mandated and resourced staffing for PACT, the papers by True, Forman, Tuepker and colleagues found that leaders at other levels were not able to ensure that staffing was adequate or that team membership remained stable and collocated. Without sufficient, consistent and collocated staff, these papers report that not only is it difficult to engage staff, but that the move to high-functioning care teams is undercut.

Resistance to change is common in system transformation, ${ }^{6}$ and often relates to the required alterations in staff roles. In the PACT, the paper by Rodriguez et al. found that leadership needs to establish core role descriptions for the newly formed teams and effectively manage resistance to these changes. This is made complex, however, because of the flexibility teams need to shape roles in light of individual differences and other contextual factors. It is made even more complex by the VHA's departmental structures. To achieve PCMH goals, multiple papers in this supplement show that leaders need to assure that strategies, tools, and processes are aligned across departments, such as those related to clinical informatics, performance measurement and feedback, human resources, behavioral health, practice leadership, training, and quality improvement, to name a few.

Deploying evidence-based quality improvement strategies gives teams tools to adjust structures and processes to meet their goals. PCMH demonstrations use a variety of quality change and improvement stratetegies such as Lean, ${ }^{7}$ practice facilitation, ${ }^{8}$ and learning collaboratives, ${ }^{5}$ but there is little robust evidence to guide one's choice. In this supplement, the papers by Butler, Bidassie and colleagues focus on the applicability of virtual and centrally initiated collaboratives to guide change in the PACT initiative. 
Rubenstein et al. show the success of a robust multi-level quality improvement approach that connects central change strategies to regional and local primary care practice engagement using rapid cycles of change and measurement. In the paper by Chang et al., a practice diagnostic and improvement case study brings in the local context, and shows the level of detail and trust required to integrate mental health and primary care. Any successful quality improvement strategy is dependent on a performance measurement and feedback system that is aligned with the change goals. PCMH is fundamentally a shift from individual to team performance, while most performance measurement at the VHA continued to be directed at physicians, not teams. The papers by Hysong, Kansagara and colleagues show the implications of this misalignment, and point to needed improvement in methods for monitoring, delivering and using team performance data in PCMH.

Empaneling patients and shifting to team-based rather than clinician-directed care are tightly intertwined changes in PCMH transformation. The paper by Katz et al. confirms the link between patient continuity of care with a single clinician and satisfaction, focusing on interactions characterized by good communication and shared decision making. A move from clinician-centric to teamcentric care where care activities are shared threatens to disrupt clinician-patient relationships. There is some evidence from earlier work that patients' satisfaction may be preserved with team care, but only when patients perceive teams to be high functioning with good communication. ${ }^{9}$ Therefore, several papers appropriately focus on the challenge of creating high functioning teams. Overall, the qualitative evaluation data reported in these papers show the need for early and significant support for team development. In line with the emerging literature on relational coordination, ${ }^{10}$ the analysis by True et al. reveals substantial gaps in team dynamics that impede progress. To address these gaps, the papers by Tuepker, Rodriguez, and True point to the need to devote sufficient time and opportunity for training and mutual learning.

Ensuring access of patients to their care teams is critical to PCMH for achieving both economic and quality of care goals. In the paper by Farmer et al., access (including telephone care) remains a key issue for the VHA. The potential tradeoff between access and continuity, however, poses challenges. When physicians are the sole providers for their patients, Werner and colleagues found that the absence of the physician was associated with more visits to emergency rooms. Whether PACT team-based care will mitigate this adverse effect is unknown, and will be important to quantify in future PACT evaluations.
Organized evidence-based care, care coordination, and patient-centered interactions, the three remaining PCMH change concepts, are less well-represented among the papers, and mentioned more as needed next steps rather than as issues already in play. While implementation of evidence-based guidelines has a long history at the VHA, additional guidelines and clinical process maps are needed. Farmer et al. highlight that caring for patients with often neglected chronic conditions, such as non-malignant pain, dementia, and substance abuse, causes the most frustrations for care teams. Improving care organization for these conditions will require focused attention. In general, despite a common mental health and medical record system, electronic consultation capabilities, and a large investment in mental health, Chang et al.'s paper reveals continued difficulty in achieving integrated, coordinated behavioral health care where primary care and mental health professionals collaborate closely. While technical solutions such as referral agreements and standard referral and consultation forms can undergird specialty-primary care relationships, this paper highlights the needed around common goals, trust and respect, and consistent communication that crosses the primary-mental health interface. Interventions such as common treatment plans, case conferences, and behavioral health case managers may help with these challenges. The paper by Fix et al. examines care coordination for patients with HIV, a population characterized by a single high-impact medical condition. When HIV specialty clinics functioned only to provide HIVrelated services, patients were less satisfied and their care was less coordinated than when HIV clinics assumed PACT functionalities. However, providing intensive staff support to multiple subpopulations of patients may merely fragment care inefficiently. Understanding which models work best, for which subpopulations, will be a critical next set of goals for PACT evaluators. Of concern to the success of the PACT model, no papers in this supplement focused directly on VHA efforts to promote patient-centered interactions, including encouraging patients to engage in self-management, medical decision making, and healthy behavior change. Future evaluations of these changes will be important in achieving PACT's ultimate goals of improved patient experience and health outcomes.

In total, this collection of papers highlights the complexity and the challenges of implementing a comprehensive PCMH redesign in the VHA, and focuses most on the earliest changes required for achieving the model. Given the importance of context ${ }^{11}$ and the range of implementation options, it is no wonder that the emerging evidence on PCMH benefits has been mixed. ${ }^{12}$ As PCMH implementers guide the many changes needed, it is worthwhile to consider the lessons learned here. Ultimately, it will be 
critically important to understand how the PACT initiative influences the health of American Veterans, their care experiences, and the costs of care over the next several years.

Corresponding Author: Robert J. Reid, MD, PhD; Group Health Research Institute, 1730 Minor Avenue, Suite 1600, Seattle, WA 98101, USA (e-mail: Reid.rj@ghc.org).

\section{REFERENCES}

1. Rosland AM, Nelson $\mathbf{K}$, Sun $\mathbf{H}$, et al. The patient-centered medical home in the Veterans Health Administration. Am J Manag Care. 2013;19(7):e263-272.

2. Wagner EH, Coleman K, Reid RJ, Phillips K, Abrams MK, Sugarman JR. The changes involved in patient-centered medical home transformation. Prim Care Clin Office Pract. 2012;39:241-259.

3. Nutting PA, Crabtree BF, Miller WL, Stange KC, Stewart E, Jaen C. Transforming physician practices to patient-centered medical homes: lessons from the national demonstration project. Health Aff. 2011;30(3):439-445.
4. Donahue KE, Halladay JR, Wise A, et al. Facilitators of transforming primary care: a look under the hood at practice leadership. Ann Fam Med. 2013;11(Suppl 1):S27-S33.

5. McMullen CK, Schneider J, Firemark A, Davis J, Spofford M. Cultivating engaged leadership through a learning collaborative: lessons from primary care renewal in oregon safety net clinics. Ann Fam Med. 2013;11(Suppl 1):S34-S40.

6. Taylor HA, Greene BR, Filerman GL. A conceptual model for transformational clinical leadership within primary care group practice. J Ambul Care Manag. 2010;33(2):97-107.

7. Hsu C, Coleman $\mathbf{K}$, Ross TR, et al. Spreading a patient-centered medical home redesign: a case study. J Ambul Care Manag. 2012;35(2):99-108.

8. Nutting PA, Crabtree BF, Stewart EE, et al. Effect of facilitation on practice outcomes in the national demonstration project model of the patient-centered medical home. Ann Fam Med. 2010;8(Suppl_1):S33-44.

9. Rodriguez HP, Rogers WH, Marshall RE, Safran DG. Multidisciplinary primary care teams: effects on the quality of clinician-patient interactions and organizational features of care. Med Care. 2007;45(1):19-27.

10. Gittell JH, Godfrey M, Thistlethwaite J. Interprofessional collaborative practice and relational coordination: improving healthcare through relationships. J Interprof Care. 2013;27(3):210-213.

11. Tomoaia-Cotisel A, Scammon DL, Waitzman NJ, et al. Context matters: the experience of 14 research teams in systematically reporting contextual factors important for practice change. Ann Fam Med. 2013;11(Suppl 1):S115-123.

12. Jackson GL, Powers BJ, Chatterjee R, et al. The patient-centered medical home: a systematic review. Ann Intern Med. 2013;158(3):169178. 